\title{
UNIVERSAL VOLTAGE-MODE BIQUADRATIC FILTER SYNTHESIS USING NODAL ADMITTANCE MATRIX EXPANSION
}

\section{Tran Huu Duy ${ }^{a}$, Nguyen Duc Hoa ${ }^{b}$, Nguyen Dang Chien ${ }^{a}$, Nguyen Van Kien ${ }^{b}$, Hung-Yu Wang}

${ }^{a}$ The Faculty of Physics, Dalat University, Lamdong, Vietnam

${ }^{b}$ The Faculty of Nuclear Engineering, Dalat University, Lamdong, Vietnam

${ }^{c}$ The Faculty of Electronic Engineering, National Kaohsiung University of Applied Sciences, Taiwan

\section{Article history}

Received: May $05^{\text {th }}, 2016 \mid$ Received in revised form: July $15^{\text {th }}, 2016$

Accepted: August $30^{\text {th }}, 2016$

\begin{abstract}
This paper presents a systematic synthesis procedure for generating universal voltagemode biquadratic filters based on the nodal admittance matrix expansion. The obtained eight equivalent circuits can realize all five standard filter functions namely lowpass, bandpass, highpass, notch and allpass employing only two active elements. The obtained circuits offer the following advantages: five inputs and two outputs, simple circuit configuration, orthogonal controllability between pole frequency and quality factor, and low active and passive sensitivities. The workability of some synthesized filters is verified by HSPICE simulations to demonstrate the usefulness of the proposed method.
\end{abstract}

Keywords: Nodal admittance matrix expansion; Nullor-mirror element; Universal biquadratic filter; Voltage-mode.

\section{INTRODUCTION}

Due to the capability to realize simultaneously more than one basic filter function with the same topology, continued researches have focused on realizing universal filters. Many multi-input/multi-output universal biquads were presented (Chen, 2010; Horng, 2004; Horng, 2001; Chang et al., 1999; Chang, 1997; Chang et al., 2004; Wang et al., 2001). However, most papers have included only one novel circuit, little attention has been paid to the design of universal filters in a systematic way.

Recently, a symbolic framework for systematic synthesis of linear active circuit without any detailed prior knowledge of the circuit form was proposed (Haigh et al., 2006; Haigh, 2006; Haigh et al., 2005; Haigh \& Radmore, 2006; Saad \& Soliman, 2008). This method, called nodal admittance matrix (NAM) expansion, is very useful to 
generate various novel circuits in a systematic way. Based on this synthesizing method of active network, the generation of several oscillators, trans-impedance, current-mode and voltage-mode filters has been proposed (Li, 2013; Tan et al., 2013; Soliman, 2011; Tran et al., 2015; Soliman, 2010). The synthesis procedure of voltage-mode filters proposed in Haigh (2006) is suitable to synthesize discrete transfer functions with different circuit topologies. It is difficult to synthesize multiple filter functions using an identical topology. The simplified systematic synthesis of current-mode universal filters using NAM expansion was reported in Soliman (2011). The synthesis of voltage-mode high-Q biquadratic notch filter was reported recently (Tran et al., 2015). However, the systematic construction method for deriving multi-function filter is not available in the literature, to the authors' knowledge.

In this paper, an expanded work of our proposed method in Tran et al. (2015) for synthesis of universal voltage-mode biquadratic filters based on NAM expansion is presented. The obtained filters with five inputs and two outputs can be used to realize five generic filter functions. They comprising two active elements possess low active and passive sensitivities characteristics. The resonance angular frequency and quality factor can be adjusted orthogonally. Two derived filters are verified by HSPICE simulations for illustration. The simulated results confirm the workability of the derived circuits and hence reveal the feasibility of the proposed approach.

\section{DESCRIPTION OF THE PROPOSED METHOD}

To synthesize universal filter circuits using NAM expansion, the denominator $\mathrm{D}(\mathrm{s})$ of a transfer function with desired specifications is chosen and it should be expressed as an admittance matrix in NAM equations as shown in (1).

$$
\left[\begin{array}{cccccc}
\mathrm{y}_{1,1} & \mathrm{y}_{1,2} & \ldots & \mathrm{y}_{1, j} & \ldots & \mathrm{y}_{1, \mathrm{~N}} \\
\mathrm{y}_{2,1} & \mathrm{y}_{2,2} & \ldots & \mathrm{y}_{2, \mathrm{j}} & \ldots & \mathrm{y}_{2, \mathrm{~N}} \\
\vdots & \vdots & \ldots & \vdots & \ldots & \vdots \\
\mathrm{y}_{\mathrm{i}, 1} & \mathrm{y}_{\mathrm{i}, 2} & \ldots & \mathrm{y}_{\mathrm{i}, \mathrm{j}} & \ldots & \mathrm{y}_{\mathrm{i}, \mathrm{N}} \\
\vdots & \vdots & \ldots & \vdots & \ldots & \vdots \\
\mathrm{y}_{\mathrm{N}, 1} & \mathrm{y}_{\mathrm{N}, 2} & \ldots & \mathrm{y}_{\mathrm{N}, \mathrm{j}} & \ldots & \mathrm{y}_{\mathrm{N}, \mathrm{N}}
\end{array}\right]
$$

This matrix can be used as a starting matrix in NAM expansion to find the circuit configuration with no input signals (Tran et al., 2015). 
For the voltage-mode filter in Wang et al. (2010), it is observed that the reduced admittance matrix of a voltage-mode circuit after applying symbolic analysis includes node 1 as input node and other nodes as output nodes (Wang et al., 2010). This matrix also contains admittance terms of numerator of the transfer function of a circuit in the first column. Since the inputted voltage source can be represented by its equivalent circuit shown in Figure 1, we can obtain the expanded NAM of a synthesized circuit with injected voltage source equivalent circuit. In addition, each appeared passive element in matrix (1) can be used to inject the input voltage source, thus the circuit topology of a universal filter with multi-input property represented by the form of matrix (1) can be obtained. The procedure to synthesize voltage-mode universal filters can be summarized as below (Tran et al., 2015).

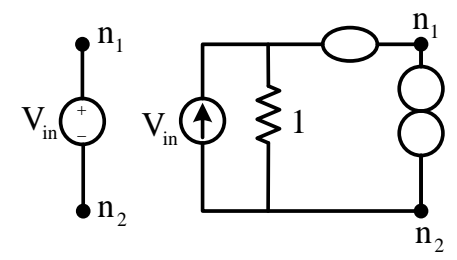

Figure 1. R-nullor equivalent circuit of a voltage source

Step 1) Introduce a row and a column of zero terms to row 1 and column 1 , and add a unity grounded resistor to position $(1,1)$ of $(1)$. The existing columns and rows are moved to the right and to the bottom, as given by (2).

$$
\left[\begin{array}{ccccccc}
1 & 0 & 0 & \cdots & 0 & \cdots & 0 \\
0 & \mathrm{y}_{1,1} & \mathrm{y}_{1,2} & \cdots & \mathrm{y}_{1, \mathrm{j}} & \cdots & \mathrm{y}_{1, \mathrm{~N}} \\
0 & \mathrm{y}_{2,1} & \mathrm{y}_{2,2} & \cdots & \mathrm{y}_{2, \mathrm{j}} & \cdots & \mathrm{y}_{2, \mathrm{~N}} \\
\vdots & \vdots & \vdots & \cdots & \vdots & \cdots & \vdots \\
0 & \mathrm{y}_{\mathrm{i}, 1} & \mathrm{y}_{\mathrm{i}, 2} & \cdots & \mathrm{y}_{\mathrm{i}, \mathrm{j}} & \cdots & \mathrm{y}_{\mathrm{i,N}} \\
\vdots & \vdots & \vdots & \cdots & \vdots & \cdots & \vdots \\
0 & \mathrm{y}_{\mathrm{N}, 1} & \mathrm{y}_{\mathrm{N}, 2} & \cdots & \mathrm{y}_{\mathrm{N}, \mathrm{j}} & \cdots & \mathrm{y}_{\mathrm{N}, \mathrm{N}}
\end{array}\right]
$$

Step 2) Use the Cramer's rule; add appeared admittance terms to the first column of matrix (2) to estimate the numerator of the desired transfer function of filter such as lowpass, bandpass, highpass, notch and allpass. This operation is equivalent to the injecting of input voltage signal to the added admittance terms in column 1 . The adding of admittance terms to the first column will not affect the denominator of the 
transfer function. For example, the matrix (3) can be obtained according to Step 2 by adding term $\pm \mathrm{y} 11$.

$$
\left[\begin{array}{ccccccc}
1 & 0 & 0 & \cdots & 0 & \cdots & 0 \\
\pm \mathrm{y}_{1,1} & \mathrm{y}_{1,1} & \mathrm{y}_{1,2} & \cdots & \mathrm{y}_{1, \mathrm{j}} & \cdots & \mathrm{y}_{1, \mathrm{~N}} \\
0 & \mathrm{y}_{2,1} & \mathrm{y}_{2,2} & \cdots & \mathrm{y}_{2, \mathrm{j}} & \cdots & \mathrm{y}_{2, \mathrm{~N}} \\
\vdots & \vdots & \vdots & \cdots & \vdots & \cdots & \vdots \\
0 & \mathrm{y}_{\mathrm{i}, 1} & \mathrm{y}_{\mathrm{i}, 2} & \cdots & \mathrm{y}_{\mathrm{i}, \mathrm{j}} & \cdots & \mathrm{y}_{\mathrm{i}, \mathrm{N}} \\
\vdots & \vdots & \vdots & \cdots & \vdots & \cdots & \vdots \\
0 & \mathrm{y}_{\mathrm{N}, 1} & \mathrm{y}_{\mathrm{N}, 2} & \cdots & \mathrm{y}_{\mathrm{N}, \mathrm{j}} & \cdots & \mathrm{y}_{\mathrm{N}, \mathrm{N}}
\end{array}\right]
$$

Step 3) Introduce a column and a row of zero terms to column 2 and row 2 of the matrix (3) and place the infinity variables to the admittance matrix to realize the equivalent circuit of voltage source in Figure 1. Therefore, a nullator between column 1 and column 2 and a norator between row 2 and ground are introduced. The matrix (3) becomes (4).

$$
\left[\begin{array}{cccccccc}
1 & 0 & 0 & 0 & 0 & 0 & 0 & 0 \\
-\infty_{1} & \infty_{1} & 0 & 0 & 0 & 0 & 0 & 0 \\
\pm \mathrm{y}_{1,1} & 0 & \mathrm{y}_{1,1} & \mathrm{y}_{1,2} & \ldots & \mathrm{y}_{1, \mathrm{j}} & \ldots & \mathrm{y}_{1, \mathrm{n}} \\
0 & 0 & \mathrm{y}_{2,1} & \mathrm{y}_{2,2} & \ldots & \mathrm{y}_{2, \mathrm{j}} & \ldots & \mathrm{y}_{2, \mathrm{n}} \\
\vdots & \vdots & \vdots & \vdots & \ldots & \vdots & \ldots & \vdots \\
0 & 0 & \mathrm{y}_{\mathrm{i}, 1} & \mathrm{y}_{\mathrm{i}, 2} & \ldots & \mathrm{y}_{\mathrm{i}, \mathrm{j}} & \ldots & \mathrm{y}_{2, \mathrm{n}} \\
\vdots & \vdots & \vdots & \vdots & \ldots & \vdots & \ldots & \vdots \\
0 & 0 & \mathrm{y}_{\mathrm{n}, 1} & \mathrm{y}_{\mathrm{n}, 2} & \ldots & \mathrm{y}_{\mathrm{n}, \mathrm{j}} & \ldots & \mathrm{y}_{\mathrm{n}, \mathrm{n}}
\end{array}\right]
$$

Step 4) Expand the obtained matrix (4) to find the complete admittance matrix of the synthesized circuit (Haigh, 2006; Saad \& Soliman, 2008).

It can be observed that in NAM expansion process, we need to introduce row and column of zero terms and infinity-variables with a common node on the main diagonal in order to move the admittance elements to their correct form in admittance matrix. Thus, four types of CCIIs with a common node at terminal-X are used to implement the nullor-mirror element pairs in the synthesized circuits (Tran et al., 2015).

\section{APPLICATION EXAMPLES}

We hope to synthesize biquadratic voltage mode universal filters using minimum number of passive elements with the property of orthogonal control between 
Q factor and pole frequency. Thus, the denominator of the transfer function is chosen as (5). Since several filter functions with grounded capacitors can be obtained if each capacitor is arranged to have only a single position on the main diagonal of NAM. Thus, the equation (5) can be expressed by (6) and (7) in the form of (1). Following Step 1 of the procedure in Section 2, the equivalent NAMs (8) and (9) can be obtained from (6) and (7), respectively.

$$
\begin{aligned}
& \mathrm{D}(\mathrm{s})=\mathrm{s}^{2} \mathrm{C}_{1} \mathrm{C}_{2}+\mathrm{sC}_{2} \mathrm{G}_{1}+\mathrm{G}_{2} \mathrm{G}_{3} \\
& {\left[\begin{array}{cc}
\mathrm{G}_{1}+\mathrm{sC}_{1} & -\mathrm{G}_{2} \\
\mathrm{G}_{3} & \mathrm{sC}_{2}
\end{array}\right]} \\
& {\left[\begin{array}{ccc}
\mathrm{G}_{1}+\mathrm{sC}_{1} & \mathrm{G}_{2} \\
-\mathrm{G}_{3} & \mathrm{sC}_{2}
\end{array}\right]} \\
& {\left[\begin{array}{ccc}
1 & 0 & 0 \\
0 & \mathrm{G}_{1}+\mathrm{sC}_{1} & -\mathrm{G}_{2} \\
0 & \mathrm{G}_{3} & \mathrm{sC}_{2}
\end{array}\right]} \\
& {\left[\begin{array}{ccc}
1 & 0 & 0 \\
0 & \mathrm{G}_{1}+\mathrm{sC}_{1} & \mathrm{G}_{2} \\
0 & -\mathrm{G}_{3} & \mathrm{sC}_{2}
\end{array}\right]}
\end{aligned}
$$

The matrices (8) and (9) are defined as NAM type-A and NAM type-B, respectively. They can be used as starting matrices in NAM expansion. The node 1 is chosen as input node, nodes 2 and 3 are two output nodes denoted by $\mathrm{V}_{\text {out1 }}$ and $\mathrm{V}_{\text {out2. }}$. It must be noted that the output nodes in (8) and (9) may be changed when applying Step 3 of the NAM expansion procedure in Section 2.

\subsection{Synthesis of type-A universal voltage mode circuits}

Applying Step 2, a bandpass function at $\mathrm{V}_{\text {out1 }}$ and lowpass function at $\mathrm{V}_{\text {out2 }}$ can be obtained by injecting the input voltage source to $R_{1}\left(=1 / G_{1}\right)$. This operation corresponds to the inserting of term $-\mathrm{G}_{1}$ to the first column of (8), as the following matrix. 


$$
\left[\begin{array}{ccc}
1 & 0 & 0 \\
-\mathrm{G}_{1} & \mathrm{G}_{1}+\mathrm{sC}_{1} & -\mathrm{G}_{2} \\
0 & \mathrm{G}_{3} & \mathrm{sC}_{2}
\end{array}\right]
$$

Using the Step 3, the matrix (11) can be acquired. By virtue of term $\pm \infty_{1}$ we can move term $-\mathrm{G}_{1}$ to column 2 , add elements $\pm \mathrm{G}_{1}$ to row 2 to complete the symmetrical element set for term $\mathrm{G}_{1}$ as (12). By applying Step 4, two columns and rows of zero terms are created and pairs of nullor-mirror elements represented by $\infty_{2}, \infty_{3}$ are introduced to the right and bottom of matrix (12). So the matrix (12) can be expanded as (13)

$$
\begin{aligned}
& {\left[\begin{array}{cccc}
1 & 0 & 0 & 0 \\
-\infty_{1} & \infty_{1} & 0 & 0 \\
-\mathrm{G}_{1} & 0 & \mathrm{G}_{1}+\mathrm{sC}_{1} & -\mathrm{G}_{2} \\
0 & 0 & \mathrm{G}_{3} & \mathrm{sC}_{2}
\end{array}\right]} \\
& {\left[\begin{array}{cccc}
1 & 0 & 0 & 0 \\
-\infty_{1} & \mathrm{G}_{1}+\infty_{1} & -\mathrm{G}_{1} & 0 \\
0 & -\mathrm{G}_{1} & \mathrm{G}_{1}+\mathrm{sC}_{1} & -\mathrm{G}_{2} \\
0 & 0 & \mathrm{G}_{3} & \mathrm{sC}_{2}
\end{array}\right]} \\
& {\left[\begin{array}{cccccc}
1 & 0 & 0 & 0 & 0 & 0 \\
-\infty & \mathrm{G}_{1}+\infty_{1} & -\mathrm{G}_{1} & 0 & 0 & 0 \\
0 & -\mathrm{G}_{1} & \mathrm{G}_{1}+\mathrm{sC}_{1} & -\infty_{2} & \infty_{2} & 0 \\
0 & 0 & \infty_{3} & \mathrm{sC}_{2} & 0 & -\infty_{3} \\
0 & 0 & 0 & -\infty_{2} & \mathrm{G}_{2}+\infty_{2} & 0 \\
0 & 0 & -\infty_{3} & 0 & 0 & \mathrm{G}_{3}+\infty_{3}
\end{array}\right]}
\end{aligned}
$$

The obtained filter represented by (13) is shown in Figure 2 a with nodes $V_{\text {in2, }}$ V. in3, $V_{\text {in4 }}$ and $V_{\text {in5 }}$ grounded. There are four alternative cases (cases 1-4) to introduce the pairs of various nullor-mirror elements by expanding the matrix (11) (the NAM type-A), as shown in Table 1.

Using different pathological pairs, the four nullor-mirror equivalent circuits of the derived type-A filters represented by matrices in Table 1 are shown in Figure 2 with nodes $\mathrm{V}_{\mathrm{in} 2}, \mathrm{~V}_{\mathrm{in} 3}, \mathrm{~V}_{\mathrm{in} 4}$ and $\mathrm{V}_{\text {in5 }}$ grounded. Each synthesized circuit includes two active and five passive elements. 


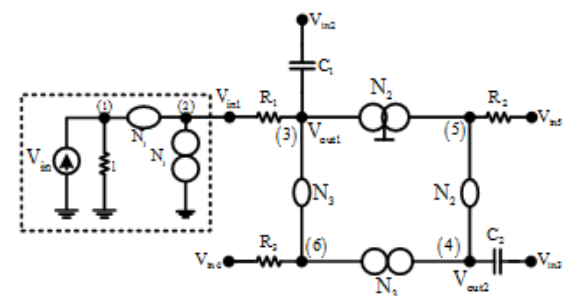

(a)

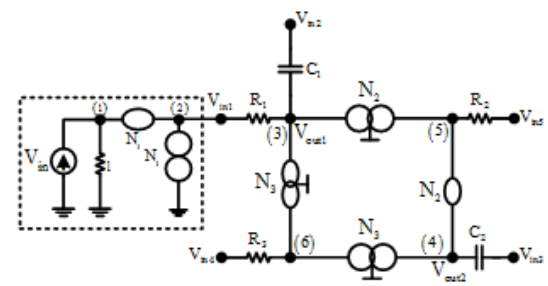

(c)

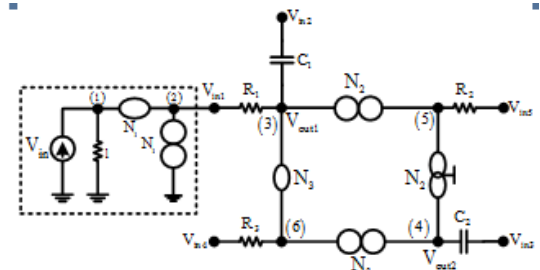

(b)

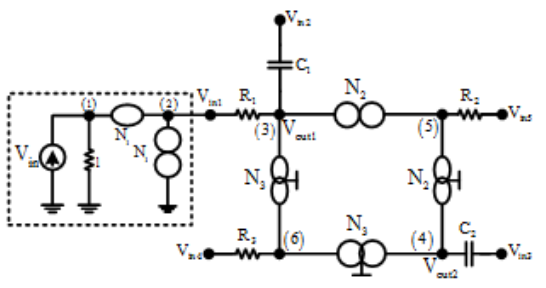

(d)

Figure 2. Pathological representations of type-A prototypes

Table 1. Four cases of expanding NAM Type-A

$\frac{\text { Expanding matrix (11) (Case 1) }}{\left[\begin{array}{cccccc}1 & 0 & 0 & 0 & 0 & 0 \\ -\infty_{1} & \mathrm{G}_{1}+\infty_{1} & -\mathrm{G}_{1} & 0 & 0 & 0 \\ 0 & -\mathrm{G}_{1} & \mathrm{G}_{1}+\mathrm{sC}_{1} & -\infty_{2} & \infty_{2} & 0 \\ 0 & 0 & \infty_{3} & \mathrm{sC}_{2} & 0 & -\infty_{3} \\ 0 & 0 & 0 & -\infty_{2} & \mathrm{G}_{2}+\infty_{2} & 0 \\ 0 & 0 & -\infty_{3} & 0 & 0 & \mathrm{G}_{3}+\infty_{3}\end{array}\right]}$

Expanding matrix (11) (Case 3)

$$
\left[\begin{array}{cccccc}
1 & 0 & 0 & 0 & 0 & 0 \\
-\infty_{1} & \mathrm{G}_{1}+\infty_{1} & -\mathrm{G}_{1} & 0 & 0 & 0 \\
0 & -\mathrm{G}_{1} & \mathrm{G}_{1}+\mathrm{sC}_{1} & -\infty_{2} & \infty_{2} & 0 \\
0 & 0 & \infty_{3} & \mathrm{sC}_{2} & 0 & \infty_{3} \\
0 & 0 & 0 & -\infty_{2} & \mathrm{G}_{2}+\infty_{2} & 0 \\
0 & 0 & \infty_{3} & 0 & 0 & \mathrm{G}_{3}+\infty_{3}
\end{array}\right]
$$

Similarly, a highpass function at $\mathrm{V}_{\text {out1 }}$ and bandpass function at $\mathrm{V}_{\text {out2 }}$ can be obtained by injecting the input voltage source to $\mathrm{C}_{1}$. This is equivalent to the inserting of term $-\mathrm{sC}_{1}$ to the first column of (8) as the following matrix (14). Using Steps 3 and 4 to introduce nullor-mirror pairs denoted by $\infty_{1}, \infty_{2}, \infty_{3}$, the matrix (14) can be expanded as (15).

$$
\left[\begin{array}{ccc}
1 & 0 & 0 \\
-\mathrm{sC}_{1} & \mathrm{G}_{1}+\mathrm{sC}_{1} & -\mathrm{G}_{2} \\
0 & \mathrm{G}_{3} & \mathrm{sC}_{2}
\end{array}\right]
$$




$$
\left[\begin{array}{cccccc}
1 & 0 & 0 & 0 & 0 & 0 \\
-\infty_{1} & \mathrm{SC}_{1}+\infty_{1} & -\mathrm{SC}_{1} & 0 & 0 & 0 \\
0 & -\mathrm{sC}_{1} & \mathrm{G}_{1}+\mathrm{sC}_{1} & -\infty_{2} & \infty_{2} & 0 \\
0 & 0 & \infty_{3} & \mathrm{sC}_{2} & 0 & -\infty_{3} \\
0 & 0 & 0 & -\infty_{2} & \mathrm{G}_{2}+\infty_{2} & 0 \\
0 & 0 & -\infty_{3} & 0 & 0 & \mathrm{G}_{3}+\infty_{3}
\end{array}\right]
$$

For the circuit in Figure 2a, moving the injected voltage source equivalent circuit to node $V_{\text {in2 }}$ with nodes $V_{\text {in } 1}, V_{\text {in3 } 3}, V_{\text {in4 }}$ and $V_{\text {ins }}$ grounded, we can obtain the filter represented by (15). Similarly, we can obtain other three type-A highpass functions at $\mathrm{V}_{\text {out1 }}$ and bandpass functions at $\mathrm{V}_{\text {out2 }}$ with injected voltage source at node $\mathrm{V}_{\text {in2}}$, as they can be observed in Figure 2(b,d).

Also, one additional bandpass function at $\mathrm{V}_{\text {out1 }}$ can be obtained by applying the input voltage source to $\mathrm{C}_{2}$. This is equivalent to the inserting of term $-\mathrm{sC}_{2}$ to the first column of (8), as given by (16). Applying Step 3 and Step 4 to introduce nullor-mirror pairs denoted by $\infty_{1}, \infty_{2}, \infty_{3}$, the matrix (16) can be expanded as (17).

$$
\begin{aligned}
& {\left[\begin{array}{ccc}
1 & 0 & 0 \\
0 & \mathrm{G}_{1}+\mathrm{sC}_{1} & -\mathrm{G}_{2} \\
-\mathrm{sC}_{2} & \mathrm{G}_{3} & \mathrm{sC}_{2}
\end{array}\right]} \\
& {\left[\begin{array}{cccccc}
1 & 0 & 0 & 0 & 0 & 0 \\
-\infty_{1} & \mathrm{sC}_{2}+\infty_{1} & 0 & -\mathrm{sC}_{2} & 0 & 0 \\
0 & 0 & \mathrm{G}_{1}+\mathrm{sC}_{1} & -\infty_{2} & \infty_{2} & 0 \\
0 & -\mathrm{sC}_{2} & \infty_{3} & \mathrm{sC}_{2} & 0 & -\infty_{3} \\
0 & 0 & 0 & -\infty_{2} & \mathrm{G}_{2}+\infty_{2} & 0 \\
0 & 0 & -\infty_{3} & 0 & 0 & \mathrm{G}_{3}+\infty_{3}
\end{array}\right]}
\end{aligned}
$$

For the circuit in Figure 2a, moving the injected voltage source equivalent circuit to node $V_{\text {in3 }}$ with nodes $V_{\text {in1 }}, V_{\text {in2 }}, V_{\text {in4 }}$ and $V_{\text {in5 }}$ grounded, we can obtain the filter represented by (17). Similarly, we can obtain other three type-A bandpass functions at $V_{\text {out } 1}$ with injected voltage source at node $V_{\text {in3 }}$, as they can be observed in Figure 2(b,d).

In addition, a lowpass function at $\mathrm{V}_{\text {out1 }}$ can be obtained by injecting the input voltage source to $R_{3}$. This operation corresponds to the inserting of term $-G_{3}$ to the first column of (8) as given by (18). By using Step 3 and Step 4 to introduce nullor-mirror pairs denoted by $\infty_{1}, \infty_{2}, \infty_{3}$, the matrix (18) can be expanded as (19). 
$\left[\begin{array}{ccc}1 & 0 & 0 \\ 0 & \mathrm{G}_{1}+\mathrm{sC}_{1} & -\mathrm{G}_{2} \\ -\mathrm{G}_{3} & \mathrm{G}_{3} & \mathrm{sC}_{2}\end{array}\right]$

$$
\left[\begin{array}{cccccc}
1 & 0 & 0 & 0 & 0 & 0 \\
-\infty_{1} & \mathrm{G}_{3}+\infty_{1} & 0 & 0 & 0 & -\mathrm{G}_{3} \\
0 & 0 & \mathrm{G}_{1}+\mathrm{sC}_{1} & -\infty_{2} & \infty_{2} & 0 \\
0 & 0 & \infty_{3} & \mathrm{sC}_{2} & 0 & -\infty_{3} \\
0 & 0 & 0 & -\infty_{2} & \mathrm{G}_{2}+\infty_{2} & 0 \\
0 & -\mathrm{G}_{3} & -\infty_{3} & 0 & 0 & \mathrm{G}_{3}+\infty_{3}
\end{array}\right]
$$

For the circuit in Figure 2a, moving the injected voltage source equivalent circuit to node $\mathrm{V}_{\text {in4 }}$ with nodes $\mathrm{V}_{\text {in1 }}, \mathrm{V}_{\text {in2 }}, \mathrm{V}_{\text {in3 }}$ and $\mathrm{V}_{\text {in5 }}$ grounded, we can obtain the filter represented by (19). Similarly, we can obtain other three type-A lowpass functions at $\mathrm{V}_{\text {out1 }}$ with injected voltage source at node $\mathrm{V}_{\text {in }}$, as they can be observed in Figure $2(b, d)$.

Besides, a bandpass function at $\mathrm{V}_{\text {out1 }}$ and lowpass function at $\mathrm{V}_{\text {out2 }}$ can be obtained by applying the input voltage source to $\mathrm{R}_{2}$. This is equivalent to the inserting of term $\mathrm{G}_{2}$ to the first column of (8) as expressed by (20). The matrix (20) can be expanded as (21).

$$
\begin{aligned}
& {\left[\begin{array}{ccc}
1 & 0 & 0 \\
\mathrm{G}_{2} & \mathrm{G}_{1}+\mathrm{sC}_{1} & -\mathrm{G}_{2} \\
0 & \mathrm{G}_{3} & \mathrm{sC}_{2}
\end{array}\right]} \\
& {\left[\begin{array}{cccccc}
1 & 0 & 0 & 0 & 0 & 0 \\
-\infty_{1} & \mathrm{G}_{2}+\infty_{1} & 0 & 0 & -\mathrm{G}_{2} & 0 \\
0 & 0 & \mathrm{G}_{1}+\mathrm{sC}_{1} & -\infty_{2} & \infty_{2} & 0 \\
0 & 0 & \infty_{3} & \mathrm{sC}_{2} & 0 & -\infty_{3} \\
0 & -\mathrm{G}_{2} & 0 & -\infty_{2} & \mathrm{G}_{2}+\infty_{2} & 0 \\
0 & 0 & -\infty_{3} & 0 & 0 & \mathrm{G}_{3}+\infty_{3}
\end{array}\right]}
\end{aligned}
$$

For the circuit in Figure 2a, moving the injected voltage source equivalent circuit to node $\mathrm{V}_{\text {in5 }}$ with nodes $\mathrm{V}_{\mathrm{in} 1}, \mathrm{~V}_{\mathrm{in} 2}, \mathrm{~V}_{\mathrm{in} 3}$ and $\mathrm{V}_{\mathrm{in} 4}$ grounded, we can obtain the filter represented by (21). In the same way, we can obtain other three type-A bandpass functions at $\mathrm{V}_{\text {out1 }}$ and lowpass functions at $\mathrm{V}_{\text {out2 }}$ with injected voltage source at node $\mathrm{V}_{\text {in5}}$, as they can be observed in Figure 2(b,d). 
A notch function at $\mathrm{V}_{\text {out1 }}$ and lowpass function at $\mathrm{V}_{\text {out2 }}$ can be obtained by inserting terms $-\mathrm{SC}_{1}$ and $-\mathrm{G}_{3}$ to the first column of (8) as (22). The matrix (22) can be expanded as (23).

$$
\begin{aligned}
& {\left[\begin{array}{ccc}
1 & 0 & 0 \\
-\mathrm{sC}_{1} & \mathrm{G}_{1}+\mathrm{sC}_{1} & -\mathrm{G}_{2} \\
-\mathrm{G}_{3} & \mathrm{G}_{3} & \mathrm{sC}_{2}
\end{array}\right]} \\
& {\left[\begin{array}{cccccc}
1 & 0 & 0 & 0 & 0 & 0 \\
-\infty_{1} & \mathrm{G}_{3}+\mathrm{sC}_{1}+\infty_{1} & -\mathrm{sC}_{1} & 0 & 0 & -\mathrm{G}_{3} \\
0 & -\mathrm{sC}_{1} & \mathrm{G}_{1}+\mathrm{sC}_{1} & -\infty_{2} & \infty_{2} & 0 \\
0 & 0 & \infty_{3} & \mathrm{sC}_{2} & 0 & -\infty_{3} \\
0 & 0 & 0 & -\infty_{2} & \mathrm{G}_{2}+\infty_{2} & 0 \\
0 & -\mathrm{G}_{3} & -\infty_{3} & 0 & 0 & \mathrm{G}_{3}+\infty_{3}
\end{array}\right]}
\end{aligned}
$$

For the circuit in Figure 2a, moving the injected voltage source equivalent circuit to the merged node of $V_{\text {in2 }}$ and $V_{\text {in4 }}$ with nodes $V_{\text {in1 }}, V_{\text {in3 }}$ and $V_{\text {in5 }}$ grounded, we can obtain the filter represented by (23). Similarly, we can obtain other three type-A notch functions at $\mathrm{V}_{\text {out1 }}$ and lowpass functions at $\mathrm{V}_{\text {out2 }}$ with injected voltage source at the merged node of $V_{\text {in2 }}$ and $V_{\text {in4 }}$, as they can be observed in Figure 2(b,d).

In addition, an allpass function at $\mathrm{V}_{\text {out1 }}$ (with $\mathrm{G}_{2}=\mathrm{G}_{1}$ ) and a lowpass function at $\mathrm{V}_{\text {out2 }}$ can be obtained by inserting terms $-\mathrm{sC}_{1}+\mathrm{G}_{2}$ and $-\mathrm{G}_{3}$ to the first column of (8). The matrix becomes

$$
\left[\begin{array}{ccc}
1 & 0 & 0 \\
-\mathrm{sC}_{1}+\mathrm{G}_{2} & \mathrm{G}_{1}+\mathrm{sC}_{1} & -\mathrm{G}_{2} \\
-\mathrm{G}_{3} & \mathrm{G}_{3} & \mathrm{sC}_{2}
\end{array}\right]
$$

Using Step 3 and Step 4, the matrix (24) can be expanded as (25). For the circuit in Figure 2a, moving the injected voltage source equivalent circuit to the merged node of $V_{\text {in2 }}, V_{\text {in4 }}$ and $V_{\text {in5 }}$ with nodes $V_{\text {in1 }}$ and $V_{\text {in3 }}$ grounded, we can obtain the filter represented by (25). Similarly, we can obtain other three type-A allpass functions at $\mathrm{V}_{\text {out1 }}$ and lowpass functions at $\mathrm{V}_{\text {out2 }}$ with injected voltage source at the merged node of

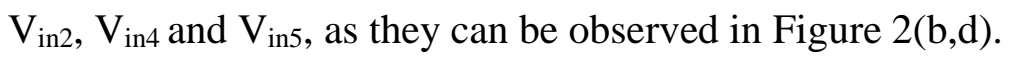




$$
\left[\begin{array}{cccccc}
1 & 0 & 0 & 0 & 0 & 0 \\
-\infty_{1} & \mathrm{G}_{2}+\mathrm{G}_{3}+\mathrm{sC}_{1}+\infty_{1} & -\mathrm{sC}_{1} & 0 & -\mathrm{G}_{2} & -\mathrm{G}_{3} \\
0 & -\mathrm{sC}_{1} & \mathrm{G}_{1}+\mathrm{sC}_{1} & -\infty_{2} & \infty_{2} & 0 \\
0 & 0 & \infty_{3} & \mathrm{sC}_{2} & 0 & -\infty_{3} \\
0 & -\mathrm{G}_{2} & 0 & -\infty_{2} & \mathrm{G}_{2}+\infty_{2} & 0 \\
0 & -\mathrm{G}_{3} & -\infty_{3} & 0 & 0 & \mathrm{G}_{3}+\infty_{3}
\end{array}\right]
$$

A highpass function at $\mathrm{V}_{\text {out2 }}$ can be obtained (with $\mathrm{C}_{1} \mathrm{G}_{3}=\mathrm{C}_{2} \mathrm{G}_{1}$ ) by inserting terms $-\mathrm{sC}_{1}$ and $-\mathrm{sC}_{2}$ to the first column of (8). The matrix becomes (26).

$$
\left[\begin{array}{ccc}
1 & 0 & 0 \\
-\mathrm{sC}_{1} & \mathrm{sC}_{1}+\mathrm{G}_{1} & -\mathrm{G}_{2} \\
-\mathrm{sC}_{2} & \mathrm{G}_{3} & \mathrm{sC}_{2}
\end{array}\right]
$$

Applying Steps 3 and 4, the matrix (26) can be expanded as (27). For the circuit in Figure 2a, moving the injected voltage source equivalent $\pm \infty_{1}$ circuit to the merged node of $\mathrm{V}_{\text {in2 }}$ and $\mathrm{V}_{\text {in3 }}$ with nodes $\mathrm{V}_{\text {in1 }}, \mathrm{V}_{\text {in4 }}$ and $\mathrm{V}_{\text {in5 }}$ grounded, we can obtain the filter represented by (27). Similarly, we can obtain other three type-A highpass functions at $\mathrm{V}_{\text {out2 }}$ with injected voltage source at the merged node of $\mathrm{V}_{\text {in2 }}$ and $\mathrm{V}_{\text {in3 }}$, as they can be observed in Figure 2(b,d).

$$
\left[\begin{array}{cccccc}
1 & 0 & 0 & 0 & 0 & 0 \\
-\infty_{1} & \mathrm{sC}_{1}+\mathrm{sC}_{2}+\infty_{1} & -\mathrm{sC}_{1} & -\mathrm{sC}_{2} & 0 & 0 \\
0 & -\mathrm{sC}_{1} & \mathrm{G}_{1}+\mathrm{sC}_{1} & -\infty_{2} & \infty_{2} & 0 \\
0 & -\mathrm{sC}_{2} & \infty_{3} & \mathrm{sC}_{2} & 0 & -\infty_{3} \\
0 & 0 & 0 & -\infty_{2} & \mathrm{G}_{2}+\infty_{2} & 0 \\
0 & 0 & -\infty_{3} & 0 & 0 & \mathrm{G}_{3}+\infty_{3}
\end{array}\right]
$$

By inserting terms $-\mathrm{sC}_{1}+\mathrm{G}_{2}$ and $-\mathrm{sC}_{2}$ to the first column of (8) as shown in (28), a notch filter at $\mathrm{V}_{\text {out2 }}$ (with $\mathrm{C}_{2} \mathrm{G}_{1}=\mathrm{C}_{1} \mathrm{G}_{3}$ ) and highpass filter at $\mathrm{V}_{\text {out1 }}$ can be obtained. By using Step 3 and Step 4, the matrix (28) can be expanded as (29).

$$
\begin{aligned}
& {\left[\begin{array}{ccc}
1 & 0 & 0 \\
-\mathrm{sC}_{1}+\mathrm{G}_{2} & \mathrm{sC}_{1}+\mathrm{G}_{1} & -\mathrm{G}_{2} \\
-\mathrm{sC}_{2} & \mathrm{G}_{3} & \mathrm{sC}_{2}
\end{array}\right]} \\
& {\left[\begin{array}{cccccc}
1 & 0 & 0 & 0 & 0 & 0 \\
-\infty & \mathrm{sC}_{1}+\mathrm{sC}_{2}+\mathrm{G}_{2}+\infty_{1} & -\mathrm{sC}_{1} & -\mathrm{sC}_{2} & -\mathrm{G}_{2} & 0 \\
0 & -\mathrm{sC}_{1} & \mathrm{G}_{1}+\mathrm{sC}_{1} & -\infty_{2} & \infty_{2} & 0 \\
0 & -\mathrm{sC}_{2} & \infty_{3} & \mathrm{sC}_{2} & 0 & -\infty_{3} \\
0 & -\mathrm{G}_{2} & 0 & -\infty_{2} & \mathrm{G}_{2}+\infty_{2} & 0 \\
0 & 0 & -\infty_{3} & 0 & 0 & \mathrm{G}_{3}+\infty_{3}
\end{array}\right]}
\end{aligned}
$$


For the circuit in Figure 2a, moving the injected voltage source equivalent circuit to the merged node of $V_{\text {in2 }}, V_{\text {in } 3}$ and $V_{\text {in5 }}$ with nodes $V_{\text {in1 }}$ and $V_{\text {in4 }}$ grounded, we can obtain the filter represented by (29). Similarly, we can obtain other three type-A notch functions at $\mathrm{V}_{\text {out2 }}$ with injected voltage source at the merged node of $\mathrm{V}_{\text {in2 }}, \mathrm{V}_{\text {in3 }}$ and $\mathrm{V}_{\text {in5 }}$ as they can be observed in Figure 2(b,d). The output functions of all the aforementioned synthesized circuits can be expressed by

$$
\begin{aligned}
& \mathrm{V}_{\text {out } 1}=\frac{\mathrm{s}^{2} \mathrm{C}_{1} \mathrm{C}_{2} \mathrm{~V}_{\text {in } 2}+\mathrm{sC}_{2} \mathrm{G}_{1} \mathrm{~V}_{\text {in } 1}+\mathrm{sC}_{2} \mathrm{G}_{2} \mathrm{~V}_{\text {in } 3} \pm \mathrm{G}_{2} \mathrm{G}_{3} \mathrm{~V}_{\text {in } 4} \pm s \mathrm{C}_{2} \mathrm{G}_{2} \mathrm{~V}_{\text {in } 5}}{\mathrm{~s}^{2} \mathrm{C}_{1} \mathrm{C}_{2}+\mathrm{sC}_{2} \mathrm{G}_{1}+\mathrm{G}_{2} \mathrm{G}_{3}} \\
& \mathrm{~V}_{\text {out } 2}=\frac{\left(\mathrm{s}^{2} \mathrm{C}_{1} \mathrm{C}_{2}+\mathrm{sC}_{2} \mathrm{G}_{1}\right) \mathrm{V}_{\text {in } 3} \pm\left(\mathrm{sC}_{1} \mathrm{G}_{3}+\mathrm{G}_{3} \mathrm{G}_{1}\right) \mathrm{V}_{\text {in } 4}-\mathrm{G}_{3} \mathrm{G}_{1} \mathrm{~V}_{\text {in } 1}-\mathrm{sC}_{1} \mathrm{G}_{3} \mathrm{~V}_{\text {in } 2} \pm \mathrm{G}_{2} \mathrm{G}_{3} \mathrm{~V}_{\text {in } 5}}{\mathrm{~s}^{2} \mathrm{C}_{1} \mathrm{C}_{2}+\mathrm{sC}_{2} \mathrm{G}_{1}+\mathrm{G}_{2} \mathrm{G}_{3}}
\end{aligned}
$$

\subsection{Synthesis of type-B universal voltage mode circuits}

Similarly, by applying Step 2, a bandpass function at $\mathrm{V}_{\text {out1 }}$ and lowpass function at $\mathrm{V}_{\text {out2 }}$ can be obtained by injecting the input voltage source to $\mathrm{R}_{1}$. This operation corresponds to the inserting of term $-G_{1}$ to the first column of (9). So (9) becomes (32). By applying Step 3 to matrix (32), the obtained matrix is shown as (33). Using Step 4, the matrix (33) can be expanded as (34).

$$
\begin{aligned}
& {\left[\begin{array}{ccc}
1 & 0 & 0 \\
-\mathrm{G}_{1} & \mathrm{G}_{1}+\mathrm{sC}_{1} & \mathrm{G}_{2} \\
0 & -\mathrm{G}_{3} & \mathrm{sC}_{2}
\end{array}\right]} \\
& {\left[\begin{array}{cccc}
1 & 0 & 0 & 0 \\
-\infty_{1} & \mathrm{G}_{1}+\infty_{1} & -\mathrm{G}_{1} & 0 \\
0 & -\mathrm{G}_{1} & \mathrm{G}_{1}+\mathrm{sC}_{1} & \mathrm{G}_{2} \\
0 & 0 & -\mathrm{G}_{3} & \mathrm{sC}_{2}
\end{array}\right]} \\
& {\left[\begin{array}{cccccc}
1 & 0 & 0 & 0 & 0 & 0 \\
-\infty & \mathrm{G}_{1}+\infty_{1} & -\mathrm{G}_{1} & 0 & 0 & 0 \\
0 & -\mathrm{G}_{1} & \mathrm{G}_{1}+\mathrm{sC}_{1} & \infty_{2} & -\infty_{2} & 0 \\
0 & 0 & -\infty_{3} & \mathrm{sC}_{2} & 0 & \infty_{3} \\
0 & 0 & 0 & -\infty_{2} & \mathrm{G}_{2}+\infty_{2} & 0 \\
0 & 0 & -\infty_{3} & 0 & 0 & \mathrm{G}_{3}+\infty_{3}
\end{array}\right]}
\end{aligned}
$$


Table 2. Four cases of expanding NAM Type-B

\begin{tabular}{|c|c|c|c|c|c|c|c|c|c|c|c|}
\hline \multicolumn{6}{|c|}{ Expanding matrix (33) (Case 1) } & \multicolumn{6}{|c|}{ Expanding matrix (33) (Case 2) } \\
\hline 1 & 0 & 0 & 0 & 0 & 0 & 1 & 0 & 0 & 0 & 0 & 0 \\
\hline$-\infty_{1}$ & $\mathrm{G}_{1}+\infty_{1}$ & $-\mathrm{G}_{1}$ & 0 & 0 & 0 & $-\infty_{1}$ & $\mathrm{G}_{1}+\infty_{1}$ & $-\mathrm{G}_{1}$ & 0 & 0 & 0 \\
\hline 0 & $-\mathrm{G}_{1}$ & $\mathrm{G}_{1}+\mathrm{sC}_{1}$ & $\infty_{2}$ & $-\infty_{2}$ & 0 & 0 & $-\mathrm{G}_{1}$ & $\mathrm{G}_{1}+\mathrm{sC}_{1}$ & $\infty_{2}$ & $\infty_{2}$ & 0 \\
\hline 0 & 0 & $-\infty_{3}$ & $\mathrm{sC}_{2}$ & 0 & $\infty_{3}$ & 0 & 0 & $-\infty_{3}$ & $\mathrm{sC}_{2}$ & 0 & $\infty_{3}$ \\
\hline 0 & 0 & 0 & $-\infty_{2}$ & $\mathrm{G}_{2}+\infty_{2}$ & 0 & 0 & 0 & 0 & $\infty_{2}$ & $\mathrm{G}_{2}+\infty_{2}$ & 0 \\
\hline 0 & 0 & $-\infty_{3}$ & 0 & 0 & $\mathrm{G}_{3}+\infty_{3}$ & 0 & 0 & $-\infty_{3}$ & 0 & 0 & $\mathrm{G}_{3}+\infty_{3}$ \\
\hline \multicolumn{6}{|c|}{ Expanding matrix (33) (Case 3) } & \multicolumn{6}{|c|}{ Expanding matrix (33) (Case 4) } \\
\hline 1 & 0 & 0 & 0 & 0 & 0 & 1 & 0 & 0 & 0 & 0 & 0 \\
\hline$-\infty_{1}$ & $\mathrm{G}_{1}+\infty$ & $-\mathrm{G}_{1}$ & 0 & 0 & 0 & $-\infty_{1}$ & $\mathrm{G}_{1}+\infty_{1}$ & $-\mathrm{G}_{1}$ & 0 & 0 & 0 \\
\hline 0 & $-\mathrm{G}_{1}$ & $\mathrm{G}_{1}+\mathrm{sC}_{1}$ & $\infty_{2}$ & $-\infty_{2}$ & 0 & 0 & $-\mathrm{G}_{1}$ & $\mathrm{G}_{1}+\mathrm{sC}_{1}$ & $\infty_{2}$ & $\infty_{2}$ & 0 \\
\hline 0 & 0 & $-\infty_{3}$ & $\mathrm{sC}_{2}$ & 0 & $-\infty_{3}$ & 0 & 0 & $-\infty_{3}$ & $\mathrm{sC}_{2}$ & 0 & $-\infty_{3}$ \\
\hline 0 & 0 & 0 & $-\infty_{2}$ & $\mathrm{G}_{2}+\infty_{2}$ & 0 & 0 & 0 & 0 & $\infty_{2}$ & $\mathrm{G}_{2}+\infty_{2}$ & 0 \\
\hline 0 & 0 & $\infty_{3}$ & 0 & 0 & $\mathrm{G}_{3}+\infty_{3}$ & 0 & 0 & $\infty_{3}$ & 0 & 0 & $\mathrm{G}_{3}+\infty_{3}$ \\
\hline
\end{tabular}

The obtained filter represented by (34) is shown in Figure $3 a$ with nodes $V_{\text {in2, }}, V$. in3, $V_{\text {in4 }}$ and $V_{\text {in } 5}$ grounded. There are four alternative cases to introduce the pairs of various nullor-mirror elements by expanding the matrix (33) (the NAM type-B), as shown in Table 2. The four nullor-mirror equivalent circuits of the derived type-B filters represented by matrices in Table 2 are shown in Figure 3 with nodes $V_{\text {in2 }}, V_{\text {in } 3}, V_{\text {in } 4}$ and $V_{\text {in5 }}$ grounded. Each synthesized circuit contains two active and five passive elements.

Also, a highpass function at $\mathrm{V}_{\text {out1 }}$ and bandpass function at $\mathrm{V}_{\text {out2 }}$ can be obtained by injecting the input voltage source to $\mathrm{C}_{1}$. This operation corresponds to the inserting of term $-\mathrm{sC}_{1}$ to the first column of (9), as shown in (35). Using Steps 3 and 4, the matrix (35) can be expanded as (36).

$$
\begin{aligned}
& {\left[\begin{array}{ccc}
1 & 0 & 0 \\
-\mathrm{sC}_{1} & \mathrm{G}_{1}+\mathrm{sC}_{1} & \mathrm{G}_{2} \\
0 & -\mathrm{G}_{3} & \mathrm{sC}_{2}
\end{array}\right]} \\
& {\left[\begin{array}{cccccc}
1 & 0 & 0 & 0 & 0 & 0 \\
-\infty_{1} & \mathrm{sC}_{1}+\infty_{1} & -\mathrm{sC}_{1} & 0 & 0 & 0 \\
0 & -\mathrm{sC}_{1} & \mathrm{G}_{1}+\mathrm{sC}_{1} & \infty_{2} & -\infty_{2} & 0 \\
0 & 0 & -\infty_{3} & \mathrm{sC}_{2} & 0 & \infty_{3} \\
0 & 0 & 0 & -\infty_{2} & \mathrm{G}_{2}+\infty_{2} & 0 \\
0 & 0 & -\infty_{3} & 0 & 0 & \mathrm{G}_{3}+\infty_{3}
\end{array}\right]}
\end{aligned}
$$

For the circuit in Figure 3a, moving the injected voltage source equivalent circuit to node $V_{\text {in2 }}$ with nodes $V_{\text {in } 1}, V_{\text {in3 }}, V_{\text {in4 }}$ and $V_{\text {in5 }}$ grounded, we can obtain the 
filter represented by (36). Similarly, we can obtain other three type-B highpass functions at $\mathrm{V}_{\text {out1 }}$ and bandpass functions at $\mathrm{V}_{\text {out2 }}$ with injected voltage source at node $\mathrm{V}_{\text {in2}}$, as they can be observed in Figure 3(b,d).

Similarly, a bandpass function at $\mathrm{V}_{\text {out1 }}$ can be achieved by applying the input voltage source to $C_{2}$. This is equivalent to the inserting of term $-\mathrm{sC}_{2}$ to the first column of (9). The matrix becomes (37). By applying Steps 3 and 4, the matrix (37) can be expanded as (38).

$$
\begin{aligned}
& {\left[\begin{array}{ccc}
1 & 0 & 0 \\
0 & \mathrm{G}_{1}+\mathrm{sC}_{1} & \mathrm{G}_{2} \\
-\mathrm{sC}_{2} & -\mathrm{G}_{3} & \mathrm{sC}_{2}
\end{array}\right]} \\
& {\left[\begin{array}{cccccc}
1 & 0 & 0 & 0 & 0 & 0 \\
-\infty_{1} & \mathrm{sC}_{2}+\infty_{1} & 0 & -\mathrm{sC}_{2} & 0 & 0 \\
0 & 0 & \mathrm{G}_{1}+\mathrm{sC}_{1} & \infty_{2} & -\infty_{2} & 0 \\
0 & -\mathrm{sC}_{2} & -\infty_{3} & \mathrm{sC}_{2} & 0 & \infty_{3} \\
0 & 0 & 0 & -\infty_{2} & \mathrm{G}_{2}+\infty_{2} & 0 \\
0 & 0 & -\infty_{3} & 0 & 0 & \mathrm{G}_{3}+\infty_{3}
\end{array}\right]}
\end{aligned}
$$

For the circuit in Figure 3a, moving the injected voltage source equivalent circuit to node $V_{\text {in3 }}$ with nodes $V_{\text {in1 }}, V_{\text {in2 }}, V_{\text {in4 }}$ and $V_{\text {in5 }}$ grounded, we can obtain the filter represented by (38). Similarly, we can obtain other three type-B bandpass functions at $\mathrm{V}_{\text {out1 }}$ with injected voltage source at node $\mathrm{V}_{\text {in2, }}$, as they can be observed in Figure 3(b,d).

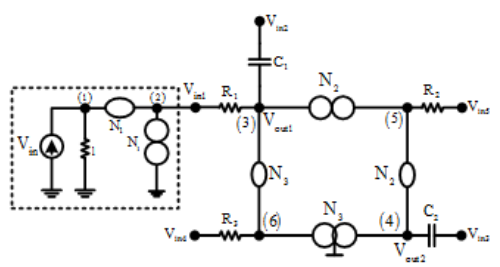

(a)

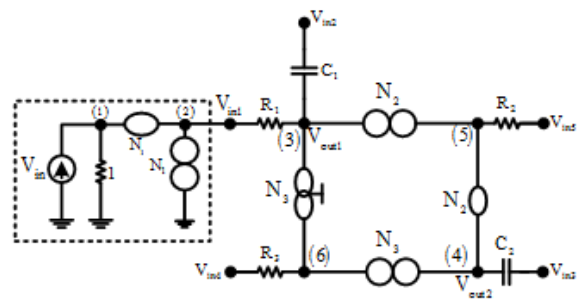

(c)

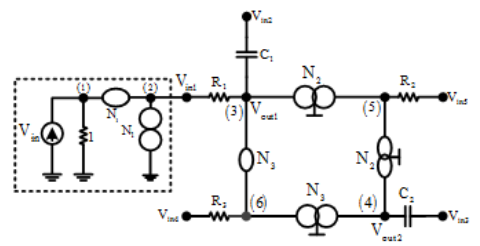

(b)

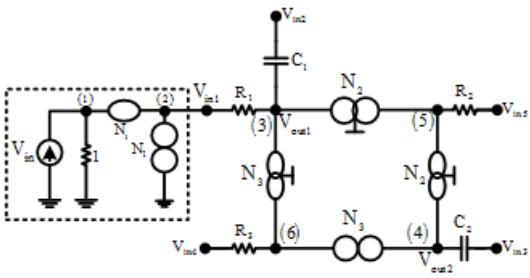

(d)

Figure 3. Pathological representations of type-B prototypes 
A lowpass function at $\mathrm{V}_{\text {out1 }}$ can be obtained by injecting the input voltage source to $R_{3}$. This operation corresponds to the inserting of term $G_{3}$ to the first column of (9), as given by (39). Using Steps 3 and 4 to, the matrix (39) can be expanded as (40).

$$
\begin{aligned}
& {\left[\begin{array}{ccc}
1 & 0 & 0 \\
0 & \mathrm{G}_{1}+\mathrm{sC}_{1} & \mathrm{G}_{2} \\
\mathrm{G}_{3} & -\mathrm{G}_{3} & \mathrm{sC}_{2}
\end{array}\right]} \\
& {\left[\begin{array}{cccccc}
1 & 0 & 0 & 0 & 0 & 0 \\
-\infty_{1} & \mathrm{G}_{3}+\infty_{1} & 0 & 0 & 0 & -\mathrm{G}_{3} \\
0 & 0 & \mathrm{G}_{1}+\mathrm{sC}_{1} & \infty_{2} & -\infty_{2} & 0 \\
0 & 0 & -\infty_{3} & \mathrm{sC}_{2} & 0 & \infty_{3} \\
0 & 0 & 0 & -\infty_{2} & \mathrm{G}_{2}+\infty_{2} & 0 \\
0 & -\mathrm{G}_{3} & -\infty_{3} & 0 & 0 & \mathrm{G}_{3}+\infty_{3}
\end{array}\right]}
\end{aligned}
$$

For the circuit in Figure 3a, moving the injected voltage source equivalent circuit to node $\mathrm{V}_{\text {in4 }}$ with nodes $\mathrm{V}_{\mathrm{in} 1}, \mathrm{~V}_{\mathrm{in} 2}, \mathrm{~V}_{\mathrm{in} 3}$ and $\mathrm{V}_{\mathrm{in} 5}$ grounded, we can obtain the filter represented by (40). Similarly, we can obtain other three type-B lowpass functions at $\mathrm{V}_{\text {out1 }}$ with injected voltage source at node $\mathrm{V}_{\text {in } 4}$, as they can be observed in Figure $3(b, d)$.

A bandpass function at $\mathrm{V}_{\text {out1 }}$ and lowpass function at $\mathrm{V}_{\text {out2 }}$ can be achieved by applying the input voltage source to $\mathrm{R}_{2}$. This operation corresponds to the inserting of term $-\mathrm{G}_{2}$ to the first column of (9), as given by (41). Applying Steps 3 and 4, the matrix (41) can be expanded as (42).

$$
\begin{aligned}
& {\left[\begin{array}{ccc}
1 & 0 & 0 \\
-\mathrm{G}_{2} & \mathrm{G}_{1}+\mathrm{sC}_{1} & \mathrm{G}_{2} \\
0 & -\mathrm{G}_{3} & \mathrm{sC}_{2}
\end{array}\right]} \\
& {\left[\begin{array}{cccccc}
1 & 0 & 0 & 0 & 0 & 0 \\
-\infty_{1} & \mathrm{G}_{2}+\infty_{1} & 0 & 0 & -\mathrm{G}_{2} & 0 \\
0 & 0 & \mathrm{G}_{1}+\mathrm{sC}_{1} & \infty_{2} & -\infty_{2} & 0 \\
0 & 0 & -\infty_{3} & \mathrm{sC}_{2} & 0 & \infty_{3} \\
0 & -\mathrm{G}_{2} & 0 & -\infty_{2} & \mathrm{G}_{2}+\infty_{2} & 0 \\
0 & 0 & -\infty_{3} & 0 & 0 & \mathrm{G}_{3}+\infty_{3}
\end{array}\right]}
\end{aligned}
$$

For the circuit in Figure 3a, moving the injected voltage source equivalent circuit to node $\mathrm{V}_{\text {in5 }}$ with nodes $\mathrm{V}_{\mathrm{in} 1}, \mathrm{~V}_{\mathrm{in} 2}, \mathrm{~V}_{\mathrm{in} 3}$ and $\mathrm{V}_{\mathrm{in}}$ grounded, we can obtain the filter represented by (42). Similarly, we can obtain other three type-B bandpass 
functions at $\mathrm{V}_{\text {out1 }}$ and lowpass functions at $\mathrm{V}_{\text {out2 }}$ with injected voltage source at node

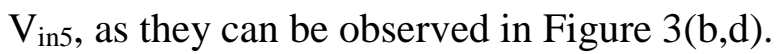

Different filter functions at $\mathrm{V}_{\text {out1 }}$ and $\mathrm{V}_{\text {out2 }}$ can be obtained by using similar method as mentioned in Section 3.1. By adding terms $-\mathrm{SC}_{1}$ and $\mathrm{G}_{3}$ to the first column of (9), notch functions at $\mathrm{V}_{\text {out1 }}$ and lowpass functions at $\mathrm{V}_{\text {out2 }}$ can be obtained. The obtained filters are shown in Figure 3 by moving the injected voltage source equivalent circuit to the merged node of $V_{\text {in2 }}$ and $V_{\text {in } 4}$ with nodes $V_{\text {in } 1}, V_{\text {in3 }}$ and $V_{\text {in5 }}$ grounded. Similarly, allpass functions at $\mathrm{V}_{\text {out } 1}$ can be obtained by inserting terms $-\mathrm{sC}_{1}$ and $\mathrm{sC}_{2}+\mathrm{G}_{3}$ to the first column of (9) with $\mathrm{G}_{2}=\mathrm{G}_{1}$.

The realized filters can be obtained from Figure 3 by moving the injected voltage source equivalent circuit to the merged node of $\mathrm{V}_{\text {in2 }}, \mathrm{V}_{\text {in3 }}$ and $\mathrm{V}_{\text {in4 }}$ with nodes $\mathrm{V}_{\text {in1 }}$ and $\mathrm{V}_{\text {in5 }}$ grounded. Also, highpass functions at $\mathrm{V}_{\text {out2 }}$ can be obtained by inserting terms $-\mathrm{G}_{1}$ and $-\mathrm{SC}_{2}+\mathrm{G}_{3}$ to the first column of (9) with $\mathrm{C}_{1} \mathrm{G}_{3}=\mathrm{C}_{2} \mathrm{G}_{1}$. The implemented filters can be shown in Figure 3 by moving the injected voltage source equivalent circuit to the merged node of $\mathrm{V}_{\text {in } 1}, \mathrm{~V}_{\text {in3 }}$ and $\mathrm{V}_{\text {in4 }}$ with nodes $\mathrm{V}_{\text {in2 }}, \mathrm{V}_{\text {in5 }}$ grounded. In addition, notch functions at $V_{\text {out2 }}$ can be obtained by adding terms $-\mathrm{G}_{1}-\mathrm{G}_{2}$ and $-{ }_{\mathrm{S}} \mathrm{C}_{2}+\mathrm{G}_{3}$ to the first column of (9) with $\mathrm{C}_{1} \mathrm{G}_{3}=\mathrm{C}_{2} \mathrm{G}_{1}$. The realized filters are shown in Figure 3 by moving the injected voltage source equivalent circuit to the merged node of $V_{\text {in1 } 1,} V_{\text {in3 }}$, $\mathrm{V}_{\text {in4 }}$ and $\mathrm{V}_{\text {in5 }}$ with nodes $\mathrm{V}_{\text {in2 }}$ grounded. The output functions of all the aforementioned synthesized circuits can be expressed by (43) and (44).

$$
\begin{aligned}
& \mathrm{V}_{\text {out } 1}=\frac{\mathrm{s}^{2} \mathrm{C}_{1} \mathrm{C}_{2} \mathrm{~V}_{\text {in } 2}+\mathrm{sC}_{2} \mathrm{G}_{1} \mathrm{~V}_{\text {in } 1}-\mathrm{sC}_{2} \mathrm{G}_{2} \mathrm{~V}_{\text {in } 3} \pm \mathrm{G}_{2} \mathrm{G}_{3} \mathrm{~V}_{\text {in } 4} \pm s \mathrm{C}_{2} \mathrm{G}_{2} \mathrm{~V}_{\text {in } 5}}{\mathrm{~s}^{2} \mathrm{C}_{1} \mathrm{C}_{2}+\mathrm{sC}_{2} \mathrm{G}_{1}+\mathrm{G}_{2} \mathrm{G}_{3}} \\
& \mathrm{~V}_{\text {out } 2}=\frac{\left(\mathrm{s}^{2} \mathrm{C}_{1} \mathrm{C}_{2}+\mathrm{sC}_{2} \mathrm{G}_{1}\right) \mathrm{V}_{\text {in } 3} \pm\left(\mathrm{sC}_{1} \mathrm{G}_{3}+\mathrm{G}_{3} \mathrm{G}_{1}\right) \mathrm{V}_{\text {in } 4}+\mathrm{G}_{3} \mathrm{G}_{1} \mathrm{~V}_{\text {in } 1}+\mathrm{sC}_{1} \mathrm{G}_{3} \mathrm{~V}_{\text {in } 2} \pm \mathrm{G}_{2} \mathrm{G}_{3} \mathrm{~V}_{\text {in } 5}}{\mathrm{~s}^{2} \mathrm{C}_{1} \mathrm{C}_{2}+\mathrm{sC}_{2} \mathrm{G}_{1}+\mathrm{G}_{2} \mathrm{G}_{3}}
\end{aligned}
$$

Figure 4 shows the practical configuration after realizing the pathological equivalents in Figure 2 and Figure 3. The used current conveyors in Figure 4 are shown in Table 3. 


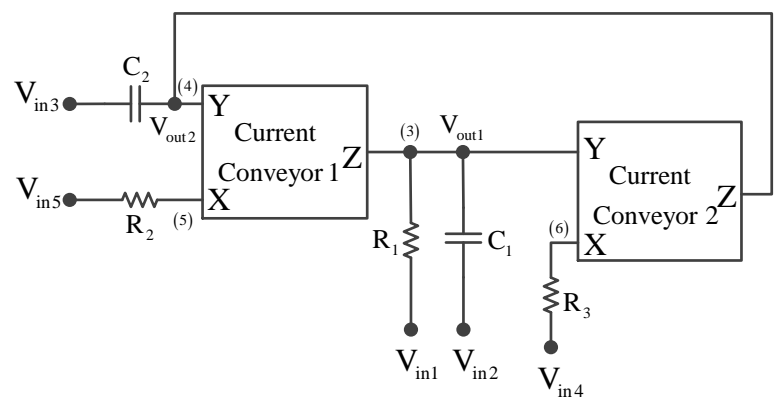

Figure 4. The realized voltage-mode universal filter configuration

Table 3. The used current conveyors in Figure 4

\begin{tabular}{llll}
\hline Type & Figure & Current conveyor 1 & Current conveyor 2 \\
\hline A(a) & $3(a)$ & CCII+ & CCII- \\
A(b) & $3(b)$ & ICCII- & CCII- \\
A(c) & $3(c)$ & CCII+ & ICCII+ \\
A(d) & $3(d)$ & ICCII- & ICCII+ \\
B(a) & $4(a)$ & CCII- & CCII+ \\
B(b) & $4(b)$ & ICCII+ & CCII+ \\
B(c) & $4(c)$ & CCII- & ICCII- \\
B(d) & $4(d)$ & ICCII+ & ICCII- \\
\hline
\end{tabular}

\subsection{Non-ideal effect of active elements}

Taking the non-idealities of current conveyors and inverting current conveyors into account, namely $\mathrm{I}_{\mathrm{Z}}= \pm \alpha \mathrm{I}_{\mathrm{X}}, \mathrm{V}_{\mathrm{X}}= \pm \beta \mathrm{V}_{\mathrm{Y}}$, where $\alpha=1-\mathrm{e}_{\mathrm{i}}$ and $\mathrm{e}_{\mathrm{i}}\left(\left|\mathrm{e}_{\mathrm{i}}\right|<<1\right)$ denotes the current tracking error, $\beta=1-\mathrm{e}_{\mathrm{v}}$ and $\mathrm{e}_{\mathrm{v}}\left(\left|\mathrm{e}_{\mathrm{v}}\right|<<1\right)$ denotes the voltage tracking error. The denominator of nonideal voltage transfer function of all obtained filters becomes

$$
\mathrm{D}(\mathrm{s})=\mathrm{s}^{2} \mathrm{C}_{1} \mathrm{C}_{2}+\mathrm{sC}_{2} \mathrm{G}_{1}+\alpha_{1} \alpha_{2} \beta_{1} \beta_{2} \mathrm{G}_{2} \mathrm{G}_{3}
$$

The frequency and the $\mathrm{Q}$ factor of all obtained filters are expressed by

$$
\omega_{0}=\sqrt{\frac{\alpha_{1} \alpha_{2} \beta_{1} \beta_{2} \mathrm{G}_{2} \mathrm{G}_{3}}{\mathrm{C}_{1} \mathrm{C}_{2}}}, \quad \mathrm{Q}=\frac{1}{\mathrm{G}_{1}} \sqrt{\frac{\alpha_{1} \alpha_{2} \beta_{1} \beta_{2} \mathrm{C}_{1} \mathrm{G}_{2} \mathrm{G}_{3}}{\mathrm{C}_{2}}}
$$

The active and passive sensitivities of $\omega_{0}$ and $\mathrm{Q}$ are shown as

$$
\begin{aligned}
& \mathrm{S}_{\alpha_{1}, \alpha_{2}, \beta_{1}, \beta_{2}}^{\omega_{0}}=S_{\alpha_{1}, \alpha_{2}, \beta_{1}, \beta_{2}}^{\mathrm{Q}}=\frac{1}{2} ; \mathrm{S}_{\mathrm{G}_{1}}^{\omega_{0}}=0 \\
& \mathrm{~S}_{\mathrm{G}_{2}, \mathrm{G}_{3}}^{\omega_{0}}=-S_{\mathrm{C}_{1}, \mathrm{C}_{2}}^{\omega_{0}}=S_{\mathrm{C}_{1}, \mathrm{G}_{2}, \mathrm{G}_{3}}^{\mathrm{Q}}=-\mathrm{S}_{\mathrm{C}_{2}}^{\mathrm{Q}}=\frac{1}{2}, \quad \mathrm{~S}_{\mathrm{G}_{1}}^{\mathrm{Q}}=-1
\end{aligned}
$$


It can be seen that all active and passive sensitivities are small. By selecting $\mathrm{C}_{1}=$ $\mathrm{C}_{2}=\mathrm{C}$ then $\mathrm{Q}$ and $\omega_{0}$ become independently adjustable by $\mathrm{R}_{1}$ and $\mathrm{C}$, respectively.

\section{SIMULATION RESULTS}

To verify the workability of the proposed method, HSPICE simulations using TSMC $035 \mu \mathrm{m}$ process parameters were performed for two of the obtained type-A and type-B filters. The CMOS implementation of the CCII \pm shown in Figure 5 was used for the simulations (Acar \& Huntman, 1999).

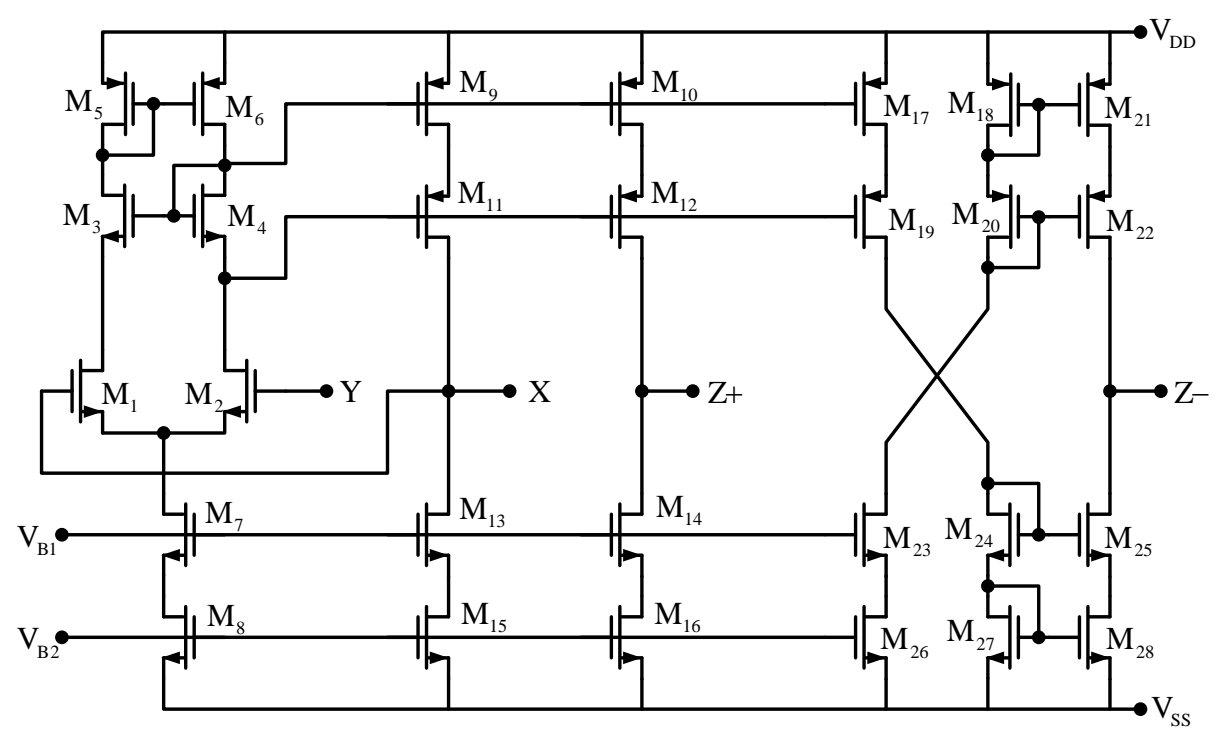

Figure 5. The CMOS circuit of CCII \pm

The aspect ratios of each NMOS and PMOS transistor are $(\mathrm{W} / \mathrm{L}=5 \mu \mathrm{m} / 1 \mu \mathrm{m})$ and $(\mathrm{W} / \mathrm{L}=10 \mu \mathrm{m} / 1 \mu \mathrm{m})$, respectively (Chen, 2010). The supply voltages of the CCII \pm are $\mathrm{V}_{\mathrm{DD}}=-\mathrm{V}_{\mathrm{SS}}=1.65 \mathrm{~V}$ with the biasing voltages $\mathrm{V}_{\mathrm{B} 1}=-0.25 \mathrm{~V}$ and $\mathrm{V}_{\mathrm{B} 2}=-0.85 \mathrm{~V}$. The filter in Figure 4 (for the type-A(a) and type-B(a) in Table 3) is used for the simulations. The simulations are realized with frequency $\mathrm{f}_{0}=1 \mathrm{MHz}$. The values of capacitors are chosen as $\mathrm{C}_{1}=\mathrm{C}_{2}=10 \mathrm{pF}$ for all simulations. The values of resistors are given by $R_{1}=11.26 \mathrm{k} \Omega$ and $R_{2}=R_{3}=15.92 \mathrm{k} \Omega$ for the simulations of lowpass, bandpass and highpass filters to obtain $\mathrm{Q}=0.707$ for maximally flat magnitude responses of lowpass and highpass functions. With node $\mathrm{V}_{\text {in1 }}$ as input node and nodes $\mathrm{V}_{\text {in2}}, \mathrm{V}_{\text {in3 }}, \mathrm{V}_{\text {in }}$ and $\mathrm{V}_{\text {in5 }}$ grounded, the frequency responses for the type-A(a) lowpass and bandpass outputs are shown in Figures 6 and 7, respectively. 
With node $\mathrm{V}_{\text {in2 }}$ as input node and nodes $\mathrm{V}_{\text {in } 1}, \mathrm{~V}_{\text {in3 }}, \mathrm{V}_{\text {in4 }}$ and $\mathrm{V}_{\text {in5 }}$ grounded, the frequency response of the type-B(a) highpass output is shown in Figure 8. Figure 9 shows the frequency response for the type-B(a) notch filter with the merged node of $\mathrm{V}_{\text {in2 }}$ and $\mathrm{V}_{\text {in } 4}$ as input node and nodes $\mathrm{V}_{\text {in } 1}, \mathrm{~V}_{\text {in } 3}$ and $\mathrm{V}_{\text {in } 5}$ grounded. The $\mathrm{R}_{1}=79.62 \mathrm{k} \Omega$ and $R_{2}=R_{3}=15.92 \mathrm{k} \Omega$ are adopted with quality factor $\mathrm{Q}=5$. Figure 10 shows the frequency responses of the type-A(a) allpass filter with merged node of $\mathrm{V}_{\text {in2 }}, \mathrm{V}_{\text {in4}}$, and $\mathrm{V}_{\text {in5 }}$ as input node and $\mathrm{V}_{\text {in1 }}$ and $\mathrm{V}_{\text {in3 }}$ grounded. The $\mathrm{R}_{1}=\mathrm{R}_{2}=11.26 \mathrm{k} \Omega$ and $\mathrm{R}_{3}=22.52$ $\mathrm{k} \Omega$ is used. All the simulated results are consistent with our theoretical prediction. The workability of the synthesized filters is verified.

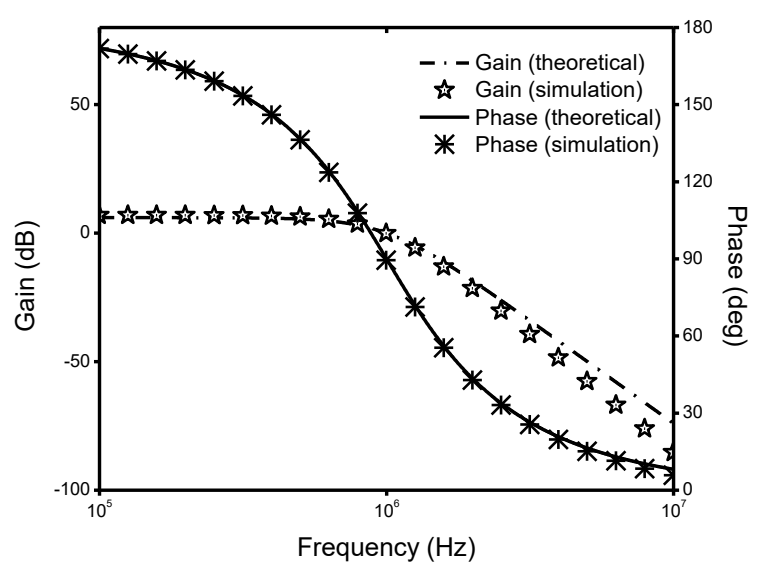

Figure 6. Frequency responses of the lowpass function in Figure 4

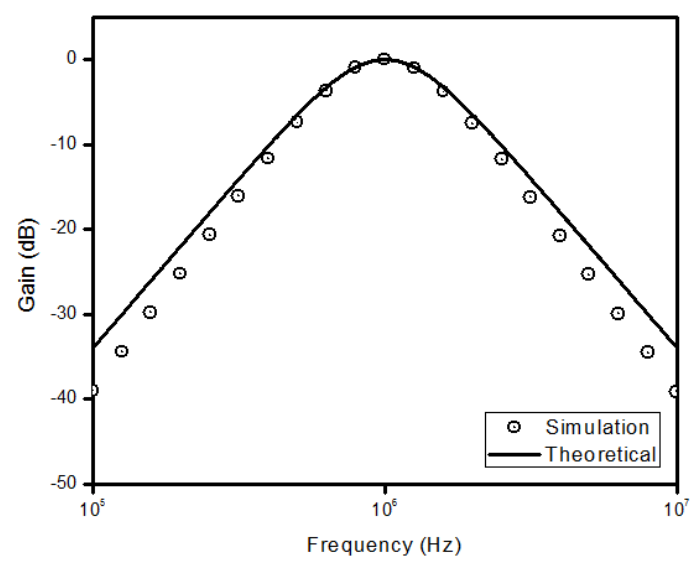

Figure 7. Frequency response of the bandpass function in Figure 4 


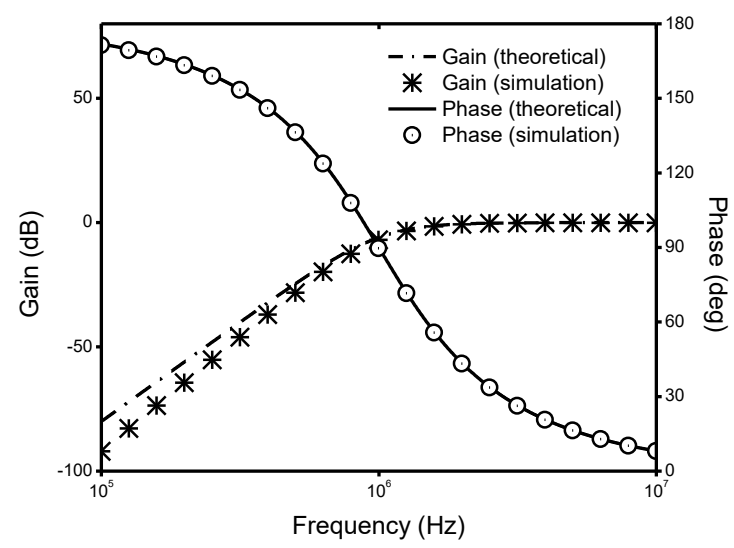

Figure 8. Frequency response of the highpass function in Figure 4

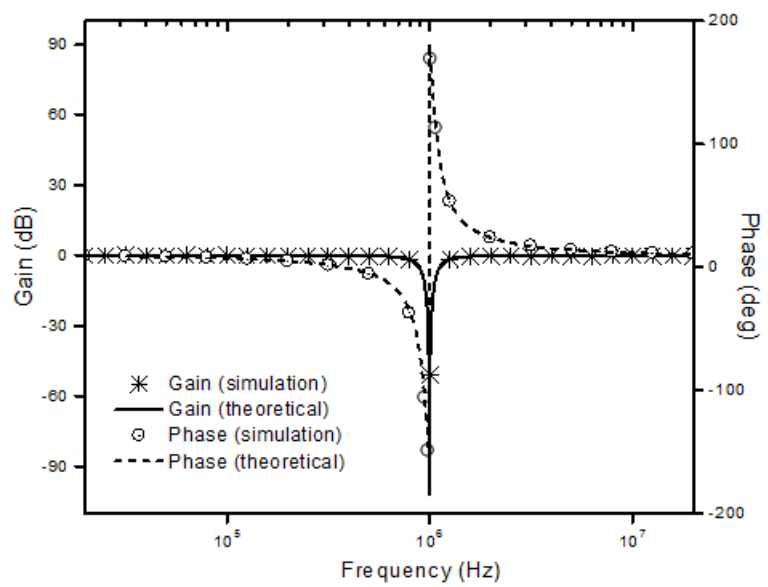

Figure 9. Frequency response of the notch filter in Figure 4

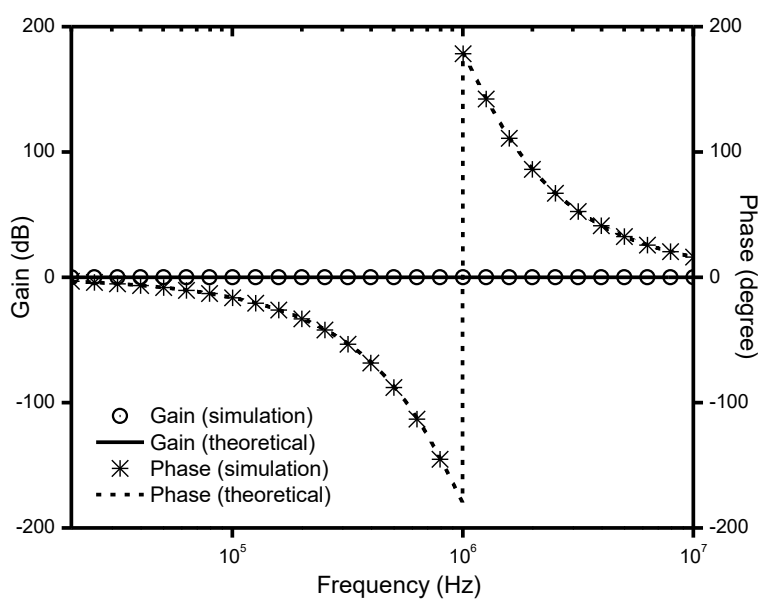

Figure 10. Frequency response of the allpass filter in Figure 4 


\section{CONCLUSION}

A systematic synthesis procedure for synthesizing universal voltage-mode biquadratic filters has been proposed in this paper. The proposed approach is based on the nodal admittance matrix expansion method using nullor-mirror pathological elements. The obtained filters with five inputs and two outputs can realize all five generic functions. HSPICE simulated results show the workability of some synthesized circuits and the feasibility of the proposed approach is confirmed.

\section{REFERENCES}

Chen, H. P. (2010). Single CCII-based voltage-mode universal filter. Analog Integrated Circuits and Signal Processing, 62(2), 259-262.

Horng, J. W. (2004). High-input impedance voltage-mode universal biquadratic filters with three inputs using plus-type CCIIs. International Journal of Electronics, 91(8), 465-475.

Horng, J. W. (2001). High-input impedance voltage-mode universal biquadratic filters using three plus-type CCIIs. IEEE Transactions on Circuits and Systems II: Analog and Digital Signal Processing, 48(10), 996-997.

Chang, C. M., \& Tu, S. H. (1999). Universal voltage mode filter with four inputs and one output using two CCII+s. International Journal of Electronics, 86(3), 305309.

Chang, C. M. (1997). Multifunction biquadratic filters using current conveyors. IEEE Transactions on Circuits and Systems II: Analog and Digital Signal Processing, 44(11), 956-958.

Chang, C. M., Al-Hashimi, B. M., \& Ross, J. N. (2004). Unified active filter biquad structures. IEE Proceedings - Circuits, Devices and Systems, 151(4), 273-277.

Wang, H. Y., \& Lee, C. T. (2001). Versatile insensitive current-mode universal biquad implementation using current conveyors. IEEE Transactions on Circuits and Systems II, 48(4), 409-413.

Haigh, D. G., Clarke, T. J. W., \& Radmore, P. M. (2006). Symbolic framework for linear active circuits based on port equivalence using limit variables. IEEE Transactions on Circuits and Systems I, 53(9), 2011-2024.

Haigh, D. G. (2006). A method of transformation from symbolic transfer function to active-RC circuit by admittance matrix expansion. IEEE Transactions on Circuits and Systems I, 53(12), 2715-2728.

Haigh, D. G., Tan, F. Q., \& Papavassiliou, C. (2005). Systematic synthesis of active-RC circuit building-blocks. Analog Integrated Circuits and Signal Processing, 43(3), 297-315. 
Haigh, D. G., \& Radmore, P. M. (2006). Admittance matrix models for the nullor using limit variables and their application to circuit design. IEEE Transactions on Circuits and Systems I, 53(10), 2214-2223.

Saad, R. A., \& Soliman, A. M. (2008). Use of mirror elements in the active device synthesis by admittance matrix expansion. IEEE Transactions on Circuits and Systems I, 55, 2726-2735.

Li, Y. A. (2013). On the systematic synthesis of OTA-based Wien oscillators. AEUInternational Journal of Electronics and Communications, 67(9), 754-760.

Tan, L., \& et al. (2013). Trans-impedance filter synthesis based on nodal admittance matrix expansion. Circuits Systems and Signal Processing, 32, 1467-1476.

Soliman, A. M. (2011). Generation of current mode filters using NAM expansion. International Journal of Circuit Theory and Applications, 19, 1087-1103.

Tran, H. D., \& et al. (2015). High-Q biquadratic notch filter synthesis using nodal admittance matrix expansion. AEU-International Journal of Electronics and Communications, 69, 981-987.

Soliman, A. M. (2010). Two integrator loop filters: generation using NAM expansion and review. Journal of Electrical and Computer Engineering. http://dx.doi.org/10.1155/2010/108687.

Wang, H. Y., Huang, W. C., \& Chiang, N. H. (2010). Symbolic nodal analysis of circuits using pathological elements. IEEE Transactions on Circuits and Systems II, 57, 874-877.

Acar, C., \& Kuntman, H. (1999). Limitations on input signal level in voltage-mode active-RC filters using current conveyors. Microelectronics Journal, 30, 69-76. 


\title{
TỔNG HợP MẠCH LọC ĐA NĂNG SỬ DỤNG PHƯƠNG PHÁP MỞ RỘNG MA TRẬN
}

\section{Trần Hữu Duy ${ }^{a^{*}}$, Nguyễn Đức Hòab ${ }^{b}$ Nguyễn Đăng Chiến ${ }^{a}$, Nguyễn Văn Kiên ${ }^{b}$, Hung-Yu Wangc}

\author{
${ }^{a}$ Khoa Vật lý, Trưòng Đại học Đà Lạt, Lâm Đồng, Việt Nam \\ ${ }^{b}$ Khoa Kỹ thuật Hạt nhân, Truờng Đại hoc Đà Lạt, Lâm Đồng, Việt Nam \\ ${ }^{c}$ Khoa Kỹ thuật Điện tử, Đại học Quốc gia Khoa học Ứng dụng Cao Hùng, Đài Loan (Trung Quốc) \\ "Tác giả liên hệ: Email: duytd@dlu.edu.vn \\ Lịch sử bài báo \\ Nhận ngày 05 tháng 05 năm 2016 | Chỉnh sửa ngày 15 tháng 07 năm 2016 \\ Chấp nhận đăng ngày 30 tháng 08 năm 2016
}

\section{Tóm tắt}

Bài báo này trình bày một thuật toán tổng hợp có hệ thống nhằm tạo ra các mach lọc đa năng bậc hai chế độ điện áp trên cơ sở phuơng pháp mở rộng ma trận. Tám mạch tương đương được tạo ra có thể thực hiện tất cả năm chức năng lọc co bản là lowpass, bandpass, highpass, notch và allpass sủ dụng chỉ hai linh kiện tích cưcc. Các mạch được tạo ra có những chức năng lợi thế sau: 5 lối vào và 2 lối ra, cấu hình mach đơn giản, tần số và hệ số $Q$ có thể điều khiển trục giao nhau, độ nhay với nhiễu của linh kiện tích cực và thu động thấp. Sự hoạt động của các mạch tạo ra được kiểm chứng bằng hệ phần mềm mô phỏng HSPICE, chứng minh tính hũu dụng của phương pháp đề xuất.

Từ khóa: Nodal admittance matrix expansion; Nullor-mirror element; Universal biquadratic filter; Voltage-mode. 